07.2

\title{
Квантово-каскадные лазеры с распределенным брэгговским отражателем, сформированным методом ионно-лучевого травления
}

\author{
(C) А.В. Бабичев ${ }^{1}$, Д.А. Пашнев ${ }^{2,3}$, А.Г. Гладышев ${ }^{4}$, Д.В. Денисов ${ }^{5}$, Г.В. Вознюк ${ }^{1}$, Л.Я. Карачинский ${ }^{1,4,6}$, \\ И.И. Новиков ${ }^{1,4,6}$, М.И. Митрофранов ${ }^{1}$, В.П. Евтихиев ${ }^{1}$, Д.А. Фирсов ${ }^{2}$, Л.Е. Воробьев ${ }^{2}$, Н.А. Пихтин $^{1}$, \\ А.Ю. Егоров ${ }^{6}$
}

${ }^{1}$ Физико-технический институт им. А.Ф. Иофрфе РАН, Санкт-Петербург, Россия

${ }^{2}$ Санкт-Петербургский политехнический университет Петра Великого, Санкт-Петербург, Россия

${ }^{3}$ Center for Physical Sciences and Technology, Vilnius, Lithuania

${ }^{4} \mathrm{OOO} \mathrm{„Коннектор} \mathrm{Оптикс“,} \mathrm{Санкт-Петербург,} \mathrm{Россия}$

${ }^{5}$ Санкт-Петербургский государственный электротехнический университет „ЛЭТИ“, Санкт-Петербург, Россия

${ }^{6}$ Университет ИТМО, Санкт-Петербург, Россия

E-mail: a.babichev@mail.ioffe.ru

Поступило в Редакцию 29 ноября 2019г.

В окончательной редакции 24 декабря 2019 г.

Принято к публикации 25 декабря 2019г.

\begin{abstract}
Продемонстрирована одночастотная лазерная генерация квантово-каскадных лазеров с распределенным брэгговским отражателем, сформированным методом ионно-лучевого травления в слоях верхней обкладки волновода. Активная область сформирована на основе гетеропары твердых растворов $\mathrm{In}_{0.53} \mathrm{Ga}_{0.47} \mathrm{As} / \mathrm{Al}_{0.48} \mathrm{In}_{0.52} \mathrm{As}$ с двухфононным опустошением нижнего уровня в каскаде. Одночастотная генерация при температуре $280 \mathrm{~K}$ соответствовала длине волны излучения $7.74 \mu \mathrm{m}$, коэффициент подавления боковых мод составил $24 \mathrm{~dB}$.
\end{abstract}

Ключевые слова: сверхрешетки, квантово-каскадный лазер, эпитаксия, фосфид индия.

DOI: 10.21883/PJTF.2020.07.49211.18135

К настоящему времени представлен ряд подходов по формированию одночастотных квантово-каскадных лазеров (ККЛ). Формирование решетки на поверхности волновода, обеспечивающей распределенную обратную связь (РОС), позволило впервые реализовать одночастотный режим генерации в ККЛ [1]. Конструкция внешнего резонатора дала возможность реализовать перестройку длины волны излучения в широком диапазоне [2]. Альтернативные подходы по селекции оптических мод высшего порядка основаны на использовании фотонных кристаллов [3], интерферометров Маха-Цендера, кольцевых [4], связанных [5,6], а также монолитно связанных резонаторов [7-9].

Формирование РОС-лазеров обеспечивает высокий коэффициент подавления боковых мод (SMSR). В свою очередь невозможность точного задания длины резонатора при скалывании зеркал приводит к непреднамеренному сдвигу фазы. Как следствие, в спектре генерации возникают дополнительные моды, что снижает процент выхода годных приборов [10]. Использование распределенных брэгговских отражателей (РБО) [11-14] исключает эффект пространственного выжигания дыр (,spatial hole burning“6), наблюдаемый в длинных РОС-лазерах. Ранее одночастотный режим генерации в ККЛ с РБО был реализован в спектральном диапазоне 4.5-5.0 $\mu \mathrm{m}[11,13]$.

В настоящей работе представлены результаты по формированию и исследованию ККЛ с РБО спектрального диапазона 7.5-8.0 $\mu \mathrm{m}$, работающих при комнатной температуре. Гетероструктура ККЛ была выращена на подложке InP с ориентацией (001) компанией „Коннектор Оптикс“ на промышленной установке молекулярно-пучковой эпитаксии Riber 49 [15,16]. Использована конструкция волновода с тонкой верхней обкладкой толщиной $750 \mathrm{~nm}$ на основе фосфида индия. Активная область сформирована на основе гетеропары твердых растворов $\operatorname{In}_{0.53} \mathrm{Ga}_{0.47} \mathrm{As} / \mathrm{Al}_{0.48} \mathrm{In}_{0.52} \mathrm{As}$ с двухфононным опустошением нижнего уровня в каскаде [17].

Формирование кристалла ККЛ проводилось по методике, аналогичной описанной ранее [18]. Использована конструкция глубокой мезы с затравом в подложку. Ширина полоска вблизи поверхности гетероструктуры составила $20 \mu \mathrm{m}$, длина лазерного резонатора $L=1.5 \mathrm{~mm}$. Отражающее и антиотражающее покрытия на сколотые грани лазера не наносились. Монтаж кристалла производился подложкой на медный теплоотвод при помощи индиевого припоя. Травление решетки РБО вблизи заднего зеркала лазера (рис. 1) проведено в сверхвысоком вакууме фокусированным пучком ионов галлия с энергией $30 \mathrm{keV}$ (рабочий ток $450 \mathrm{pA}$ ), сфокусированным в пятно диаметром $40 \mathrm{~nm}$; величина шероховатости травленой поверхности не превышала $2 \mathrm{~nm}$ [19]. Доза облучения области РБО при травлении составляла $1.75 \mathrm{pC} / \mathrm{cm}^{2}$. Период решетки РБО был равен $1.14 \mu \mathrm{m}$. Скважность решетки была выбрана равной 50\% [20]. При ширине штриха решетки $0.57 \mu \mathrm{m}$ длина штриха в перпендикулярном направлении составила $10 \mu \mathrm{m}$. Было нанесено 176 штрихов с суммарной длиной области решетки РБО, 

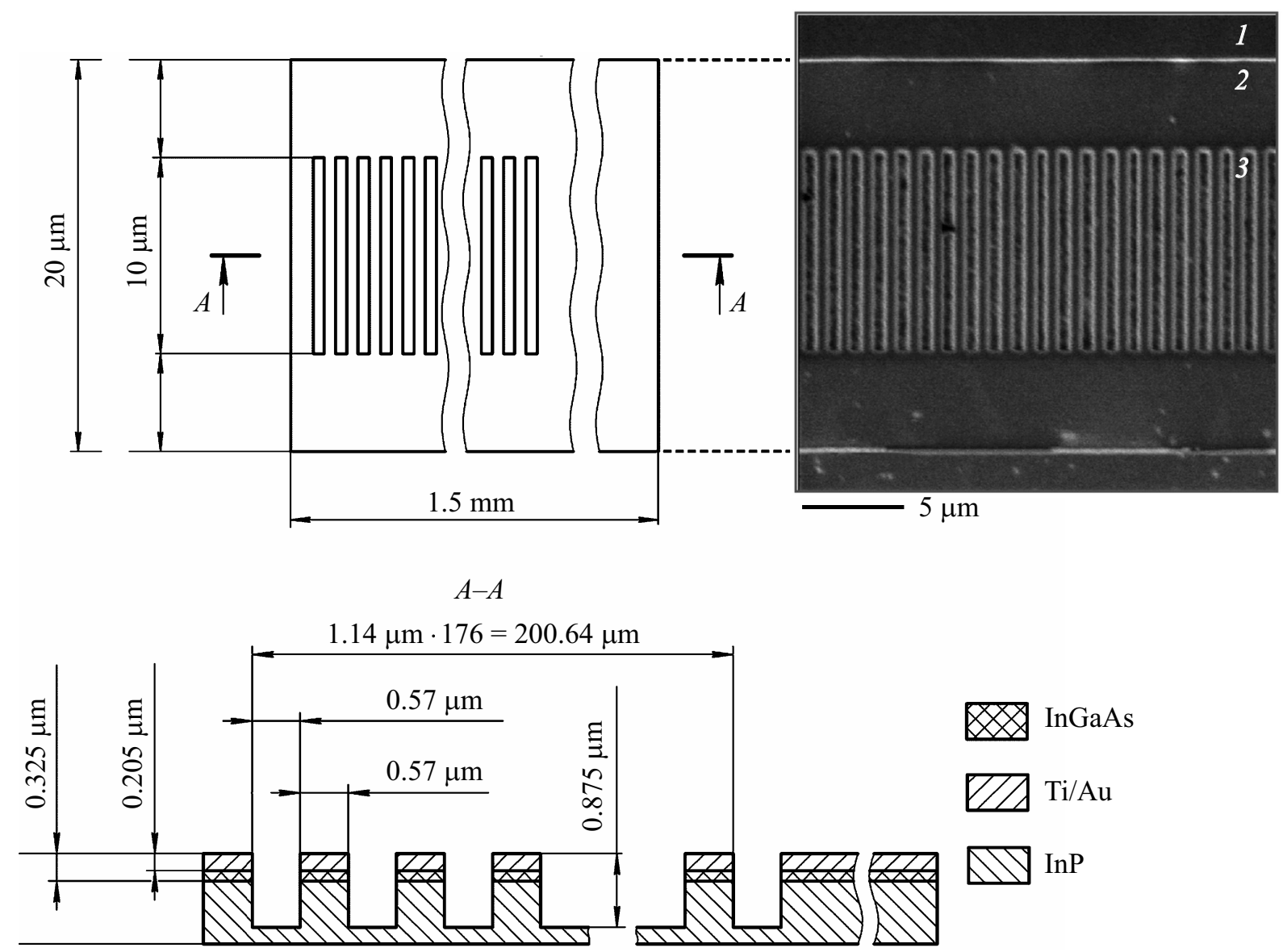

Рис. 1. Схематический вид области РБО (вид сверху и вид сбоку), а также СЭМ-изображение области РБО (вид сверху). 1 область вблизи края полоска, покрытая диэлектриком, с последующим нанесением металлизации на ее поверхность, $2-$ область токовой накачки лазера, 3 - область решетки РБО.

равной $200.64 \mu \mathrm{m}$. В области решетки РБО проведено удаление верхней металлизации толщиной $205 \mathrm{~nm}$, контактного слоя $\mathrm{In}_{0.53} \mathrm{Ga}_{0.47} \mathrm{As}$ толщиной $120 \mathrm{~nm}$, а также части верхней обкладки волновода на глубину $550 \mathrm{~nm}$. Суммарная глубина при травлении РБО составила порядка $875 \mathrm{~nm}$. Изображение сформированной решетки РБО, полученное методом сканирующей электронной микроскопии (СЭМ), представлено на рис. 1.

Вольт-амперные характеристики измерялись при пропускании импульсов тока длительностью $125 \mathrm{~ns}$ с частотой следований $15 \mathrm{kHz}$. Типичный вид вольт-амперной и ватт-амперной характеристик ККЛ с РБО, измеренных при $280 \mathrm{~K}$, представлен на рис. 2. Пороговый ток и плотность порогового тока составили $2.65 \mathrm{~A}$ и $8.6 \mathrm{kA} / \mathrm{cm}^{2}$ соответственно. Пороговый ток лазера до вытравливания решетки РБО был равен 1.7 А. Таким образом, формирование решетки РБО привело к увеличению порогового тока на 55\%, что может быть связано не только с оптическими потерями, вносимыми РБО, но и с радиационными дефектами при бомбардировке поверхности ионами галлия во время процесса травления РБО.

Спектры стимулированного излучения ККЛ измерялись с помощью фурье-спектрометра Bruker Vertex 80v.
Спектральное разрешение составляло $0.2 \mathrm{~cm}^{-1}$. Детектирование оптического сигнала проводилось с помощью охлаждаемого фотоприемника $\mathrm{HgCdTe}$ (быстродействие порядка $10 \mathrm{~ns})$. Сигнал с фотодетектора измерялся внешним аналого-цифровым преобразователем каждые $10 \mathrm{~s}$ с синхронизацией по импульсам тока и усреднялся по 20 измерениям [21]. Длительность и частота повторения импульсов составили $125 \mathrm{~ns}$ и $15 \mathrm{kHz}$ соответственно.

На рис. 3 представлены спектры лазерного излучения, измеренные при $280 \mathrm{~K}$. При токе накачки $2.65 \mathrm{~A}$ в спектре генерации вблизи $7.74 \mu \mathrm{m}$ наблюдаются три продольные оптические моды, отстоящие друг от друга на расстояние 5.4-5.8 nm, что соответствует межмодовому расстоянию резонатора Фабри-Перо длиной $1.5 \mathrm{~mm}$. Коэффициент подавления боковых мод составил $7 \mathrm{~dB}$. Ширина линий на полувысоте (FWHM) равнялась $1.7 \mathrm{~nm}$. Повышение уровня токовой накачки до 2.73 А приводит к подавлению боковых мод и возникновению одночастотной генерации с SMSR на уровне $24 \mathrm{~dB}$ (рис. 3). Значение FWHM составило $1.7 \mathrm{~nm}$. Увеличение тока до 2.8 А приводит к снижению величины SMSR до $15 \mathrm{~dB}$. При токе накачки $3 \mathrm{~A}$ и выше в спектре генерации 


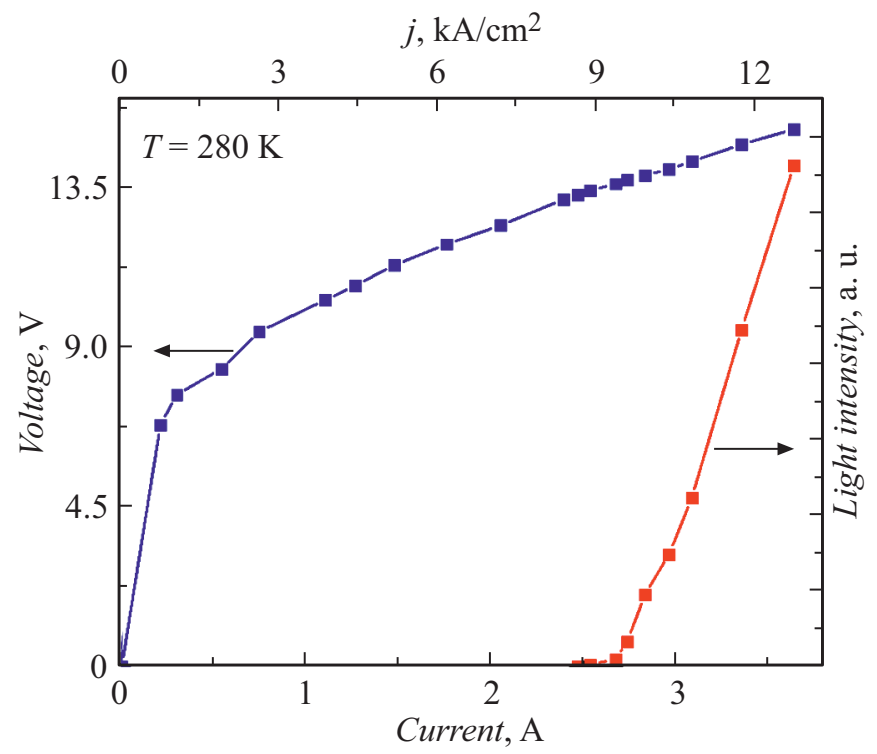

Рис. 2. Вольт-амперная характеристика ККЛ с РБО (левая ось) и ватт-амперная характеристика ККЛ с РБО (правая ось).
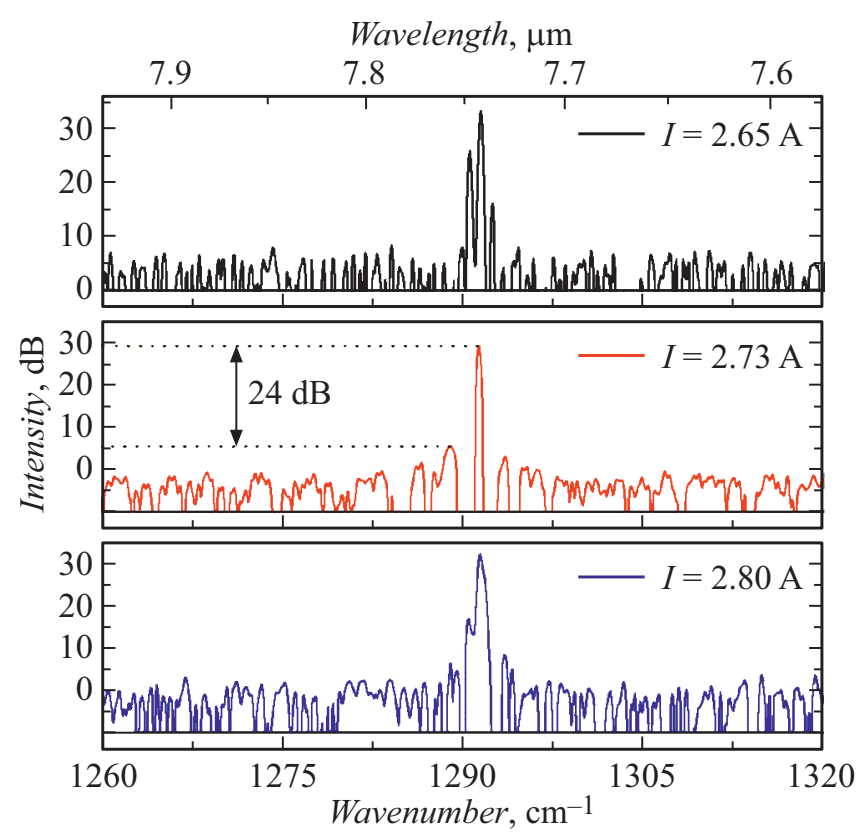

Рис. 3. Спектры генерации ККЛ с РБО при различном уровне токовой накачки.

наблюдаются дополнительные оптические моды вблизи $7.77 \mu \mathrm{m}$.

Таким образом, представлены результаты по формированию и исследованию параметров ККЛ с решеткой РБО спектрального диапазона 7.5-8.0 $\mu \mathrm{m}$. Продемонстрирована одночастотная генерация при температуре $280 \mathrm{~K}$ на длине волны излучения $7.74 \mu \mathrm{m}$. Максимально достигнутый коэффициент подавления боковых мод составил $24 \mathrm{~dB}$. Ширина линии на полувысоте в спектре лазерной генерации составила $0.3 \mathrm{~cm}^{-1}$, что обеспечивает возможность изготовления перестраиваемых источников лазерного излучения среднего инфракрасного диапазона на основе линейки одночастотных ККЛ с решетками РБО, которые требуются в спектроскопии и газоанализе.

\section{Финансирование работы}

Работа выполнена при финансовой поддержке Российского фонда фундаментальных исследований в рамках научного проекта № 16-29-03289. Д.А. Фирсов, Л.Е. Воробьев благодарят за частичную поддержку исследований Минобрнауки России (государственное задание № 3.933.2017/4.6).

\section{Конфликт интересов}

Авторы заявляют, что у них нет конфликта интересов.

\section{Список литературы}

[1] Faist J., Gmachl C., Capasso F., Sirtori C., Sivco D.L., Baillargeon J.N., Cho A.Y. // Appl. Phys. Lett. 1997. V. 70. P. 2670-2672.

[2] Luo G.P., Peng C., Le H.Q., Pei S.S., Hwang W.-Y., Ishaug B., Um J., Baillargeon J.N., Lin C.-H. // Appl. Phys. Lett. 2001. V. 78. P. 2834-2836.

[3] Semmel J., Nähle L., Höfling S., Forchel A. // Appl. Phys. Lett. 2007. V. 91. P. 071104.

[4] Wu D.H., Razeghi M. // APL Mater. 2017. V. 5. P. 035505.

[5] Wakayama Y., Iwamoto S., Arakawa Y. // Appl. Phys. Lett. 2010. V. 96. P. 171104.

[6] Liu P.Q., Wang X., Gmachl C.F. // Appl. Phys. Lett. 2012. V. 101. P. 161115.

[7] Zheng M.C., Zhang Y.M., Liu P.Q., Wang X., Fan J.-Y., Troccoli M., Gmachl C.F. // Opt. Eng. 2017. V. 57. P. 011001.

[8] Бабичев А.В., Гладышев А.Г., Курочкин А.С., Дюделев В.В., Колодезный Е.С., Соколовский Г.С., Бугров В.Е., Карачинский Л.Я., Новиков И.И., Денисов Д.В., Ионов А.С., Слипченко С.О., Лютеикий А.В., Пихтин Н.А., Егоров А.Ю. // Письма в ЖТФ. 2019. Т. 45. В. 8. С. 31-33.

[9] Бабичев А.В., Пашнев Д.А., Денисов Д.В., Гладышев А.Г., Бобрецова Ю.К., Слипченко С.О., Карачинский Л.Я., Новиков И.И., Фирсов Д.А., Воробьев Л.Е., Пихтин Н.А., Егоров А.Ю. // Оптика и спектроскопия. В печати.

[10] Liu Y., Zhang J., Yan F., Jia Z., Liu F., Liang P., Zhuo N., Zhai S.-Q., Wang L.-J., Liu J.-Q., Liu S.-M., Wang Z. // Opt. Express. 2016. V. 24. P. 19545.

[11] Bismuto A., Bidaux Y., Blaser S., Terazzi R., Gresch T., Rochat M., Muller A., Bonzon C., Faist J. // Opt. Express. 2016. V. 24. P. 10694.

[12] Song S., Howard S.S., Liu Z., Dirisu A.O., Gmachl C.F., Arnold C.B. // Appl. Phys. Lett. 2006. V. 89. P. 041115.

[13] Sadeghi A., Liu P.Q., Wang X., Fan J., Troccoli M., Gmachl C.F. // Opt. Express. 2013. V. 21. P. 31012.

[14] Sergachev I., Maulini R., Gresch T., Blaser S., Bismuto A., Mïler A., Bidaux Y., Südmeyer T., Schilt S. // Opt. Express. 2017. V. 25. P. 11027. 
[15] Бабичев А.В., Гусев Г.А., Софронов А.Н., Фирсов Д.А., Воробьев Л.Е., Усикова А.А., Задиранов Ю.М., Ильинскал Н.Д., Неведомский В.Н., Дюделев В.В., Соколовский Г.С., Гладышев А.Г., Карачинский Л.Я., Новиков И.И., Егоров А.Ю. // ЖТФ. 2018. Т. 88. В. 10. С. 1559-1563.

[16] Бабичев А.В., Курочкин А.С., Колодезный Е.С., Филимонов А.В., Усикова А.А., Неведомский В.Н., Гладышев А.Г., Карачинский Л.Я., Новиков И.И., Егоров А.Ю., Денисов Д.В. // ФТП. 2018. Т. 52. В. 6. С. 597-602.

[17] Бабичев А.В., Гладышев А.Г., Денисов Д.В., Карачинский Л.Я., Новиков И.И., Boulley L., Bousseksou A., Пихтин Н.А., Егоров А.Ю. // Оптика и спектроскопия. 2019. T. 127. B. 2. C. $278-282$.

[18] Бабичев А.В., Bousseksou А., Пихтин Н.А., Тарасов И.С., Никитина Е.В., Софронов А.Н., Фирсов Д.А., Воробьев Л.Е., Новиков И.И., Карачинский Л.Я., Егоров А.Ю. // ФТП. 2016. Т. 50. В. 10. С. 1320-1324.

[19] Pozina G., Ivanov K.A., Mitrofanov M.I., Kaliteevski M.A., Morozov K.M., Levitskii I.V., Voznyuk G.V., Evtikhiev V.P., Rodin S.N. // Phys. Status Solidi B. 2019. V. 256. P. 1800631.

[20] Bousseksou A., Moreau V., Colombelli R., Sirtori C., Patriarche G., Mauguin O., Largeau L., Beaudoin G., Sagnes I. // Electron. Lett. 2008. V. 44. P. 807-808.

[21] Бабичев А.В., Пашнев Д.А., Гладышев А.Г., Курочкин А.С., Колодезный Е.С., Карачинский Л.Я., Новиков И.И., Денисов Д.В., Boulley L., Фирсов Д.А., Воробьев Л.Е., Пихтин Н.A., Bousseksou A., Егоров А.Ю. // Письма в ЖТФ. 2019. Т. 45. В. 22. C. 21-23. 